\title{
Prejudice in Disguise: Which Features Determine the Subtlety of Ethnically Prejudicial Statements?
}

\author{
Karolina Fetz ${ }^{1}$, Martin $\mathrm{Kroh}^{1,2,3}$ \\ [1] Berlin Institute for Integration and Migration Research (BIM), Humboldt-Universität zu Berlin, Berlin, Germany. [2] Faculty of Sociology, Bielefeld University, \\ Bielefeld, Germany. [3] Socio-Economic-Panel (SOEP), German Institute for Economic Research (DIW) Berlin, Berlin, Germany.
}

Journal of Social and Political Psychology, 2021, Vol. 9(1), 187-206, https://doi.org/10.5964/jspp.6381

Received: 2018-05-09 • Accepted: 2020-10-30 • Published (VoR): 2021-05-10

Handling Editors: Karolina Hansen, University of Warsaw, Warsaw, Poland; Giovanna Leone, Sapienza University of Roma, Rome, Italy

Corresponding Author: Karolina Fetz, Berlin Institute for Integration and Migration Research, Faculty of Humanities and Social Sciences, HumboldtUniversität zu Berlin, Unter den Linden 6, 10099 Berlin, Germany. E-mail: karolina.fetz@hu-berlin.de

Supplementary Materials: Materials [see Index of Supplementary Materials]

\begin{abstract}
In current immigration debates ethnic prejudice is often expressed in a subtle manner, which conceals its xenophobic content. However, previous research has only insufficiently examined the specific features that make certain ethnically prejudicial statements subtler, i.e., less readily identifiable as xenophobic, than others. The current study employs an experimental factorial survey design and assesses the subtlety of systematically manipulated prejudicial statements. Our data from a German random population sample $(\mathrm{N}=895)$ indicate that the subtlety of ethnically prejudicial statements is manipulable along the dimensions of topic, linguistic (essentialist) phrasing, and target group: Prejudicial statements that refer to culture, that are phrased weakly essentialistically, and that target Muslims were subtlest, in being evaluated as least xenophobic by the respondents. Moreover, with an increasing internal and a decreasing external motivation to respond without prejudice, individuals reacted more strongly to the variation of the statements' topic and linguistic phrasing and were thus more sensitive to features determining subtler and more blatant ways of ethnic prejudice expression. These findings contribute to a better understanding of current migration discourses, in demonstrating that the specific manner in which ethnic prejudice is communicated can camouflage the xenophobic nature of a statement, so that it is less readily recognized as prejudicial.
\end{abstract}

\section{Keywords}

subtle prejudice, ethnic prejudice, survey experiment, internal motivation to respond without prejudice, external motivation to respond without prejudice

Against the backdrop of a constant increase of international movements of people (McAuliffe \& Ruhs, 2017), immigration has become one of the most controversial issues in current public and political debates in Europe and a lot of Western countries (e.g., Berry, Garcia-Blanco, \& Moore, 2015). Even though it has been argued that egalitarianism and the condemnation of racism have become a dominant norm in many societies (e.g., Crandall, Ferguson, \& Bahns, 2013; McConahay, 1986; Pettigrew \& Meertens, 1995), these public migration discourses frequently disclose ethnic prejudice. ${ }^{1}$ However, whereas some prejudicial opinions seem to cause rather widespread indignation in openly violating

1) We employ the term 'ethnic prejudice' to refer to negative attitudes directed at ethnic, national and ethno-religious minority groups, emphasizing that (ethnic) prejudice is directed towards socially constructed categories, not necessarily congruent with the identity of the individuals targeted by the prejudice. 
anti-prejudice norms, ethnic prejudice is often voiced in a subtler manner, which camouflages its xenophobic content, thereby slipping under the radar of the public eye.

When aiming to uncover such subtle manifestations of ethnic prejudice, a crucial question to be answered is which features actually make certain prejudicial statements subtler than others, so that they are less readily identified as xenophobic. Although the trend towards more covert expressions of ethnic prejudice has been widely acknowledged within various social-psychological approaches (e.g., Kinder \& Sears, 1981; McConahay, 1986; Pettigrew \& Meertens, 1995), these have primarily focused on examining subtle prejudice in terms of an individual-level attitude. In doing so, the specific nature of subtle ethnically prejudicial statements has only been insufficiently investigated and it has remained unanswered which characteristics of single ethnically prejudicial utterances make them subtler, contributing to a concealment of their xenophobic content.

Approaching this matter, it is the goal of the present paper to investigate whether the subtlety of ethnically prejudicial statements, i.e., the extent to which they are perceived as (not) xenophobic, is manipulable and determined by specific features of these statements. For this purpose, we conducted a survey experiment, in which expressions of ethnic prejudice were systematically varied along three dimensions-topic, language (i.e., the essentialist phrasing), and target group-in order to examine the effect of this variation on the degree to which these statements are evaluated as (not) xenophobic by their recipients. Also, we investigate whether the impact of the manipulation of the ethnically prejudicial statements and hence the responsiveness to features determining subtle and more blatant ways of ethnic prejudice expression depend on individuals' motivations to respond without ethnic prejudice (Plant \& Devine, 1998). Overall, our research seeks to shed light on dynamics in current migration discourses in illuminating the nature of subtle expressions of ethnic prejudice and those characteristics that disguise their prejudicial content, making them less recognizable as xenophobic.

\section{The Subtlety of Contemporary Forms of Ethnic Prejudice}

Over the last decades a variety of approaches have examined the emergence of contemporary forms of ethnic prejudice. They share-which is in line with the basic tenets of the group norm theory (Sherif \& Sherif, 1953; see also e.g., Crandall, Eshleman, \& O'Brien, 2002; Crandall et al., 2013)-the assumption that social norms influence the expression of ethnic prejudice and argue that a general normative trend towards egalitarianism has brought about a decline of endorsement levels of old-fashioned forms of ethnic prejudice in public opinion polls, which are clearly perceived as xenophobic. Yet they suppose that racism has not vanished, but appears in subtler guises, which circumvent predominant anti-prejudice norms (e.g., Dovidio \& Gaertner, 1986; Kinder \& Sears, 1981; McConahay, 1986; McConahay, Hardee, \& Batts, 1981; Pettigrew \& Meertens, 1995). These approaches diverge, however, in their specific conceptualization of this new 'subtlety', which might be broadly distinguished based on whether contemporary ethnic prejudice is targeted more in terms of an implicit or explicit attitude.

On the one hand, approaches such as aversive racism (e.g., Dovidio, 2001; Gaertner \& Dovidio, 1986; Pearson, Dovidio, \& Gaertner, 2009) and also implicit racism conceptualize contemporary ethnic prejudice as a negative bias or implicit attitude, becoming manifest, for instance, in negative behavioral tendencies towards minority group members or within response-latency procedures. This form of ethnic prejudice is considered subtle, since the negative bias itselfand hence its harmful consequences as well as its prejudicial nature and contradiction to egalitarian norms-are often automatic and beyond the conscious awareness on the part of those holding them. On the other hand, frameworks such as modern racism (McConahay, 1986; McConahay et al., 1981), symbolic racism (Kinder \& Sears, 1981), developed in the USA, and subtle prejudice (Pettigrew \& Meertens, 1995), originating from the European context, target contemporary, subtle ethnic prejudice as an explicit, i.e., self-reported, negative attitude towards ethnic minority groups. Although taking somewhat different theoretical stances concerning the specific sets of beliefs considered to reflect this subtle form of ethnic prejudice, such as the denial of continuing discrimination (e.g., McConahay, 1986) or the exaggeration of cultural differences (Pettigrew \& Meertens, 1995), they all focus on the subtlety of consciously accessible and utterable opinions. Assuming that in an increasingly egalitarian normative climate ethnic prejudice is no longer expressed in overtly xenophobic ways, their shared goal was to develop new, more adequate ethnic prejudice scales, encompassing items or statements that better reflect contemporary ethnically prejudicial opinions, which are less readily perceived 
to be reflective of racism and hence in conflict with general anti-prejudice norms. Thus, within this conceptualization, these contemporary forms of explicit ethnic prejudice are considered subtle, since the underlying beliefs or opinions, as conscious expressions of the prejudicial attitude, are deemed to be less strongly regarded as racist or xenophobic (e.g., McConahay, 1986; McConahay et al., 1981). ${ }^{2}$

When locating the research of this article in this field, it is more closely related to the latter approaches examining contemporary ethnic prejudice in terms of an explicit attitude, since we also investigate the subtlety of single prejudicial statements, i.e., consciously expressed utterances reflecting negative attitudes towards ethnic or national minority groups. However, this study differs from and extends this line of research regarding two aspects.

First, the theoretically assumed subtlety of explicit contemporary prejudice has often been approached rather indirectly (e.g., Henry \& Sears, 2002; Kinder \& Sears, 1981; Pettigrew \& Meertens, 1995), being inferred from higher endorsement levels for the new self-report measures compared to more old-fashioned scales. Only a limited number of studies have directly assessed this subtlety, asking respondents whether they judge different social prejudices in general as socially acceptable (Crandall et al., 2002), or evaluate different scale items as socially acceptable (Manganelli Rattazzi \& Volpato, 2003; Pettigrew \& Meertens, 1996) or reflective of racist attitudes (Dickson, 2012; McConahay, 1986; McConahay et al., 1981). Following these few studies, we also directly empirically investigate the subtlety of different ethnically prejudicial statements in assessing the degree to which they are evaluated as (not) xenophobic, with those prejudicial statements that are less strongly perceived as xenophobic being relatively subtle and those that are more readily identified as xenophobic being relatively blatant.

Second, it is important to note that in contrast to previous research on subtle forms of explicit ethnic prejudice, we take an analytically different stance. Earlier research has been primarily concerned with examining subtle ethnic prejudice as an individual-level attitude (i.e., assessing individual average scores on the new self-report measures; see e.g., Zick, Pettigrew, \& Wagner, 2008, for an overview on the use of the subtle ethnic prejudice scale in Germany and other European countries) and its role in shaping intergroup relations (e.g., Rabinowitz, Sears, Sidanius, \& Krosnick, 2009). However, the specific nature of subtle prejudicial statements themselves has only been insufficiently explored and it has remained undisclosed why certain ethnically prejudicial statements are subtler than others and which characteristics might specifically determine their subtlety. The current study seeks to address this issue in switching the focus to the level of the particular ethnically prejudicial statement itself and systematically examining how different prejudicial statements are socially perceived as (not) xenophobic. This analytical shift is crucial, especially in light of current anti-immigrant discourses, in order to reveal those aspects that camouflage the xenophobic content of a prejudicial statement.

\section{Features Determining the Subtlety of Ethnically Prejudicial Statements}

Discourse-psychological and socio-scientific approaches have emphasized that ethnic prejudice is often expressed in rhetorically camouflaged ways in social interactions and public debates (e.g., Augoustinos \& Every, 2007a, 2007b; Billig, 1988; Bonilla-Silva, 2002; Condor, Figgou, Abell, Gibson, \& Stevenson, 2006; van Dijk, 1992, 2002), and other previous work suggests on a more general level that certain forms of prejudice are less readily recognized as such than others (e.g., Baron, Burgess, \& Kao, 1991; Crandall et al., 2002; Inman \& Baron, 1996; Marti, Bobier, \& Baron, 2000; Swim, Scott, Sechrist, Campbell, \& Stangor, 2003; West \& Hewstone, 2012). However, there is a lack of research that systematically assesses the specific characteristics of single ethnically prejudicial statements that might determine their subtlety, making them more or less readily identifiable as prejudicial by their recipients. To our knowledge only Mae and Carlston (2005) have approached this issue, revealing that negative statements are more readily perceived as prejudicial than positive ones.

The current study aims to address this gap in the literature and explores three dimensions as potential determinants of the subtlety of ethnically prejudicial statements along which such utterances reflecting negative attitudes towards ethnic or national minority groups can be varied, namely (i) the topic to which is referred, (ii) the (essentialist) language

2) Also the more recent framework of microaggressions (Sue et al., 2007) includes subtler manifestations of ethnic prejudice in terms of implicit biases as well as explicit, i.e., consciously uttered, statements or remarks. 
employed, and (iii) the target group towards which the statement is directed. We thus seek to examine whether variations of ethnically prejudicial statements (or prejudice items) along these three dimensions might contribute to a concealment of their prejudicial nature and hence their potential to circumvent anti-prejudice norms, in determining the degree to which these statements are (not) recognized as xenophobic.

\section{Topic}

Public migration discourses are shaped by some core themes, around which the debates and thus also emerging ethnically prejudicial arguments evolve. One dimension along which the subtlety of ethnically prejudicial statements might thus conceivably vary is the specific topic they refer to, with particular themes potentially providing prejudicial messages with a subtler guise, which conceals their xenophobic content. Within his analysis of German newspaper articles on migration, Bauder (2008) identified four most recurring topics, three of which allowed for the expression of negative prejudicial arguments and are thus considered most relevant for this study: The culture topic, encompassing arguments on the cultural (dis)integration of different ethnic or immigrant groups; the economic utility topic, relating to the potential economic benefit or burden associated with migration (e.g., regarding the welfare state/ unemployment); and the danger topic, mostly concerned with the potential harm of migration to inner security (e.g., through terrorism/ increasing crime rates). Also with regard to more recent debates in the German media on the so-called refugee crisis, Holzberg, Kolbe, and Zaborowski (2018) pinpointed economy, state security and cultural integration, particularly gender relations, as the key themes. Comparable topics were extracted for migration discourses in other European or Western countries (e.g., Caviedes, 2015, p. 913; Eberl et al., 2018; van der Linden \& Jacobs, 2017), suggesting a cross-national importance of these three themes. Thus, across different studies-although there is no complete unanimity regarding the frequency of these topics as well as other relevant subjects (see e.g., Quinsaat, 2014, for additional frames)-culture, economic utility and danger appeared as the most prevalent topics in migration and integration debates; yet, previous work is inconclusive with regard to their potentially differing subtlety. The current research thus exploratorily investigates these dominant themes as potential vehicles for the disguised expression of ethnic prejudice and examines to what extent the subtlety of ethnically prejudicial statements, as the degree to which they are perceived as (not) xenophobic, depends on whether they refer to culture, economic utility, or danger/ inner security.

\section{Language - Essentialist Phrasing}

Within current migration debates, the manner in which ethnic prejudice is expressed also strongly varies with respect to the specific wording employed by the speakers, potentially contributing to a stronger concealment of the xenophobic content of a prejudicial comment. The current study examines the linguistic phrasing of ethnically prejudicial statements as another dimension conceivably determining their subtlety and thereby specifically focuses on the essentialist language employed. Essentialism generally refers to the idea that social categories have a defining, fixed and immutable essence that is allegedly shared by all members ascribed to this social group, which can also facilitate stereotypical and prejudicial conceptions, with (negative) behaviors and attributes being generalized and attributed to the group's supposed underlying nature (e.g., Haslam, Rothschild, \& Ernst, 2000; Prentice \& Miller, 2007). Previous research has revealed that the linguistic phrasing is a powerful tool for transmitting essentialist beliefs about groups (e.g., Gelman, Ware, \& Kleinberg, 2010; Rhodes, Leslie, \& Tworek, 2012). Also, a variety of advances in social psychology, specifically research on the linguistic intergroup bias (Maass, Salvi, Arcuri, \& Semin, 1989) and the linguistic category model (Semin \& Fiedler, 1988), have stressed the importance of linguistic features for the perpetuation of (ethnic) prejudice, whereby linguistic abstraction has received considerable attention, serving as a 'tool' to create essentialist conceptions of out-groups by depicting negative behaviors and attributes as temporally stable, dispositional features of that group (e.g., Assilaméhou, Lepastourel, \& Testé, 2013; Beukeboom, 2014; Geschke, Sassenberg, Ruhrmann, \& Sommer, 2010; Wigboldus, Semin, \& Spears, 2000). Although the use of abstract-essentialist language is generally regarded as a relatively covert feature, studies have also shown that recipients are sensitive to it, in perceiving communicators who employ highly abstract, essentialist language more strongly as having biased attitudes or a communicative agenda (Douglas \& Sutton, 2006, 2010) and as less likeable when employing abstract language to describe negative behaviors (Douglas \& Sutton, 2010). Based on these findings, one could thus suspect that the use of highly abstract, essentialist 
language in negative descriptions of ethnic minorities might be more strongly regarded as derogatory to that group and thus as xenophobic than statements that are phrased less essentialistically. Exploring this idea, the current study thus investigates whether the subtlety of ethnically prejudicial statements, as the degree to which they are perceived as (not) xenophobic, depends on the essentialist language employed, ranging from statements suggesting that the target group's inferiority is potentially alterable (employing less abstract language) to statements ascribing completely immutable and naturally fixed negative attributes to the target group (using highly abstract language).

\section{Target Group}

The third dimension that the current study examines as a potential determinant of the subtlety of ethnically prejudicial statements is the group at which they are directed. Prior research has indeed demonstrated that people judge prejudices against certain social groups, in general, as more acceptable (e.g., Crandall et al., 2002; West \& Hewstone, 2012), vary in their readiness to grant equality to different social groups (Abrams, Houston, van de Vyver, \& Vasiljevic, 2015) and also form hierarchies of ethnic and immigrant groups (e.g., Hagendoorn, 1995; Snellman \& Ekehammar, 2005). Additionally, several studies underline the impact of derogatory group labels (e.g., Carnaghi \& Maass, 2007; Fasoli et al., 2016) and could show that stereotypes, prejudice, and evaluations regarding social groups vary depending on the specific label employed to refer to that group, even for different seemingly neutral labels (e.g., Hall, Phillips, \& Townsend, 2015; Kotzur, Forsbach, \& Wagner, 2017; Rios, 2013; Rios \& Ingraffia, 2016). Against the backdrop of this research, it seems likely that the label employed for the target group within an ethnically prejudicial statement might also contribute to the concealment of its xenophobic nature: The same prejudicial statement against some groups might be perceived as less xenophobic than when being directed at other groups. In order to examine this potential impact of group labels, we employ two target groups: Turks, as the largest immigrant group in Germany (Statistisches Bundesamt, 2020), and Muslims, as the predominantly discussed group in the current migration discourse in Germany (e.g., Hierl, 2012; Spielhaus, 2013). Thus, two overlapping labels are used, with the former being a somewhat narrower national group label, while the latter is broader and might be best described as an ethno-religious group label, as it has been suggested that the term 'Muslim' has become 'ethnicized', referring to people with roots in Muslim-majority countries rather than an actual religious affiliation (Hierl, 2012; Spielhaus, 2013). Both of these groups have been found to be negatively stereotyped in Germany (Asbrock, 2010), yet it has been argued that Muslims are especially problematized in the migration discourse (Hierl, 2012; Spielhaus, 2013). The current study investigates to what extent the specific label of the target group within an ethnically prejudicial statement, associated with different connotations, might affect its degree of subtlety, potentially camouflaging its prejudicial nature.

\section{The Role of Prejudice-Related Motivations}

In a second step, we seek to explore whether the impact of such a manipulation of prejudicial statements might depend on individual characteristics of the perceivers that are plausibly related to their sensitivity to features determining subtler or more blatant ways of communicating ethnic prejudice.

In this context, we consider individuals' internal motivation (IM) and external motivation (EM) to respond without prejudice (Plant \& Devine, 1998) to be of particular interest, as they were shown to determine people's efforts to engage in an active regulation of prejudiced responses (e.g., Monteith, Lybarger, \& Woodcock, 2009). Individuals with high IM attempt to avoid prejudiced responses due to internalized anti-prejudice standards as part of their personal value system. Individuals with high EM aim to control detectable prejudiced responses in order to prevent social sanctions or external disapproval. Previous research found that with increasing IM, individuals generally show lower levels of explicit, i.e., self-reported, ethnic prejudice (e.g., Devine, Plant, Amodio, Harmon-Jones, \& Vance, 2002; Plant \& Devine, 1998) and more strongly initiate self-regulatory mechanisms to reduce self-reported prejudiced responses after being made aware of own biases (e.g., Fehr \& Sassenberg, 2010). With higher EM, individual efforts to control prejudiced responses become more context-dependent. Primarily externally motivated individuals, for instance, exhibited a reduction of their explicit prejudiced responses in public settings, i.e., when possibly being evaluated as prejudiced by others, but expressed-in the sense of a 'rebound' or 'backlash effect'-even higher levels of ethnic stereotypes in private contexts (Plant \& Devine, 1998; see also Butz \& Plant, 2009, for an overview). Also, EM was generally found to be 
associated with slightly higher levels of self-reported (i.e., privately assessed) ethnic prejudice (e.g., Devine et al., 2002; Plant \& Devine, 1998). Overall and in line with self-determination theory (e.g., Deci \& Ryan, 2000; see also Legault, Green-Demers, Grant, \& Chung, 2007), previous studies indicate that especially individuals with higher IM and lower EM, i.e., a particularly self-determined motivational profile, successfully regulate their ethnically prejudicial responses across private and public contexts as well as different, i.e., explicit and implicit, measures of ethnic prejudice (Butz \& Plant, 2009; Devine et al., 2002).

Transferring these findings to the current research, we deem these motivational constructs relevant, as they might also determine individual efforts to detect ethnically prejudicial comments and thus the scrutiny with which individuals process potentially prejudicial statements, when being asked to evaluate their xenophobic content. In that sense, these motivations might affect the individual responsiveness or sensitivity to specific variations of these ethnically prejudicial statements. We reason that with increasing IM, people would engage in a more careful processing of the potentially prejudicial statements, in being personally motivated to detect ethnic prejudice. In light of previous findings showing that EM actually undermines regulation efforts in the absence of external cues for control, we assume that individuals with higher EM would-in a private survey context-make less of an effort to engage in the detection of ethnic prejudice and scrutinize the potentially prejudicial statements less thoroughly. Hence, with higher IM and lower EM, i.e., an increasingly self-determined motivation to respond without prejudice, people might-in being more strongly committed to egalitarianism and rooting out (ethnic) prejudice-process potentially prejudicial statements more vigilantly and might thus be more attentive to the specific way in which ethnic prejudice is expressed. Based on these considerations, the current study explores whether individual levels of IM and EM influence the responsiveness to features determining subtler or more blatant ways of expressing ethnic prejudice, in assessing whether the impact of the systematic variation of the prejudicial statements along the three dimensions on the degree to which these are evaluated as (not) xenophobic depends on recipients' IM and EM.

\section{Overview and Hypotheses}

In sum, the current study explores the subtlety of single ethnically prejudicial statements and to what extent it is determined by specific features of these statements. We predict that the subtlety of ethnically prejudicial statements (or items), as the degree to which these are evaluated as (not) xenophobic, can be systematically manipulated along the dimensions of topic (i.e., culture, economic utility, and danger/ inner security), language (i.e., ranging from a weakly to a strongly essentialist phrasing), and target group (i.e., Muslims and Turks). As prior research remains inconclusive regarding the subtlety of different topics, the examination of this dimension is exploratory in nature, so we did not specify a hypothesis on which of the three topics we expect to be the subtlest, i.e., evaluated as least xenophobic by the recipients. Regarding the impact of the language on subtlety, we hypothesize that prejudicial statements that are phrased in a weakly essentialist manner are evaluated as least and those phrased in a strongly essentialist way as most xenophobic. Furthermore, we expect the same prejudicial statements referring to Muslims to be subtler, in being perceived as less xenophobic, than when being directed towards Turks. Moreover, we hypothesize that the responsiveness to features determining subtle and more blatant ways of ethnic prejudice expression and thus the impact of this systematic manipulation is moderated by recipients' motivations to respond without ethnic prejudice. Specifically, we predict that with increasing IM and decreasing EM, individuals would react more sensitively and adjust their xenophobia ratings more strongly in response to the variations of the prejudice items.

\section{Method}

\section{Participants and Procedure}

Data were collected as part of a larger telephone survey among adults in Germany, conducted by a professional survey institute. ${ }^{3}$ The telephone survey mode drawing on a probability sample of the German population was chosen to get a more representative picture of the perception of prejudice in the general public. ${ }^{4}$ In comparison to face-to-faceinterviews that also permit probability sampling, telephone surveys were shown to be associated with lower social 
desirability bias (e.g., Schwarz, Strack, Hippler, \& Bishop, 1991). After excluding 28 individuals who are Muslim or have a Turkish background (i.e., being born in Turkey, or mother or father being born in Turkey) for theoretical reasonssince the prejudice items were directed towards Muslims and Turks-, and 57 participants with missing values on IM or EM, to keep the sample constant across all models in the main analyses, the final random population sample comprised 895 participants (456 women, 437 men, 2 diverse/ no indication; $M_{\text {age }}=50.01$ years, $S D=16.32$, age range: $18-87$ years) ${ }^{5}$

\section{Design and Materials}

The current study adapted the logic of factorial survey experiments, especially popular in the social sciences (e.g., Auspurg \& Hinz, 2015; Wallander, 2009), to social-psychological prejudice research. The basic idea of factorial survey (or vignette) studies is to construct evaluation objects (vignettes) that systematically vary along different dimensions (with several levels) and to randomly assign sub-sets of vignettes to respondents for evaluation. This experimental design allows to examine how these dimensions causally influence respondents' judgments.

\section{Construction of Prejudice Items}

Analogous to this rationale, we constructed ethnic prejudice items that systematically vary along the three dimensions, i.e., topic, language, and target group. The topic of the prejudicial statements was represented by the attribute supposedly characterizing the respective target group and specified with three levels: culture (referring to the value of gender equality), economic utility (referring to work ethic), and danger/ inner security (referring to the propensity to use violence). The language, i.e., the essentialist phrasing, was manipulated with four levels, varying the verb and the degree of linguistic abstraction used for the ascribed attribute: The 'weakly essentialist phrasing' suggested the target group's neediness for assistance to adapt to an allegedly superior standard set by the majority group, implying the potential alterability of the target group's inferiority. The 'rather weakly essentialist' phrasing implied difficulties of the target group in adapting to this standard, yet still suggesting that the target group could change. The 'rather strongly essentialist phrasing' translated these supposed difficulties into a negative attribute, suggesting the relative fixedness of the target group's inferiority. The 'strongly essentialist phrasing' implied the biological immutability of the attribute, supposedly characterizing the target group by nature. The target group was varied across two levels: The same prejudicial statements were either directed at Muslims or at Turks. Apart from these variations, the wording and the ethnically prejudicial core message, suggesting the inferiority of the respective target group compared to the German majority group, were held constant across all items. Multiplying all dimension levels $(3 \times 4 \times 2)$, this resulted in a total number of 24 systematically varied prejudice items. ${ }^{6}$ Three sample items are: "Muslims need particular assistance to adapt to the idea that men and women have equal rights in Germany" (Culture/ Weakly essentialist/ Muslims); "Turks are more workshy than Germans" (Economic utility/ Rather strongly essentialist/ Turks); and "Muslims are, by nature, more inclined to violence than Germans" (Danger, inner security/ Strongly essentialist/ Muslims; Table A2 in the Supplementary Materials documents the English translation of the complete item set). ${ }^{7}$ Each participant evaluated a randomized set of four prejudice items.

3) Table A1 in the Supplementary Materials additionally documents an overview of all measures included in the larger survey.

4) This study is based on a dual-frame (i.e., landline and mobile phone) sample, drawn based on the Gabler-Häder procedure (Häder \& Gabler, 1998), in which phone numbers are randomly generated and selected.

5) This study was conducted in accordance with local and institutional ethical standards and with the 1964 Helsinki declaration and its later amendments/ comparable ethical standards.

6) The number of levels specified per dimension was also based on methodological considerations. To achieve sufficient statistical power, we aimed to acquire 150 ratings per item with an aspired sample size of around 900 respondents, which could be attained with each participant rating four out of the 24 prejudice items. The manipulation of more item dimensions/ levels would have resulted in a higher number of items to be evaluated per respondent. We considered this undesirable regarding possible fatigue and learning effects.

7) We conducted an additional online survey with a convenience sample, which further validated that the systematic item variations were indeed effective in manipulating the intended levels of the topic and language (i.e., essentialist phrasing) dimension. More detailed results are presented in the Supplementary Materials (pp. 11-17). 


\section{Measures}

\section{Xenophobia Ratings}

The subtlety of the systematically manipulated prejudicial statements was measured by asking participants whether they evaluate the four randomly selected items as xenophobic on a 1 (not xenophobic at all) to 5 (very xenophobic) scale. Xenophobia ratings were analyzed as separate observations clustered within individuals and thus not averaged per respondent.

\section{Internal and External Motivation to Respond Without Prejudice}

Participants' motivations to respond without prejudice were assessed with two items with high factor loadings (as indicated by Plant \& Devine, 1998) selected from the IM (e.g., "I attempt to act in nonprejudiced ways toward migrants because it is personally important to me") and the EM scale (e.g., "I attempt to appear nonprejudiced toward migrants in order to avoid disapproval from others"), translated into German and rephrased to assess motivations to control prejudice towards migrants. Respondents indicated their agreement with these statements on a 1 (completely disagree) to 5 (completely agree) scale (IM: $M=4.53, S D=0.75, \alpha=.75 ; r=.61, p<.001$; and EM: $M=3.23, S D=1.25, \alpha=.55 ; r=.38, p$ $<.001)^{8}{ }^{8}$

\section{Data Structure and Analysis Strategy}

Within this study, the prejudice items-not the individual participants-represented the units of analysis, with xenophobia ratings (as the indicator of subtlety) as the dependent variable and the manipulated item dimensions as the independent variables. With each respondent giving xenophobia ratings for four randomly assigned prejudice items, the data exhibited a hierarchical structure, as it is mostly the case in factorial survey experiments (see e.g., Auspurg \& Hinz, 2015): After excluding missing values using listwise deletion, 3,555 xenophobia ratings (Level 1) were clustered within 895 respondents (Level 2). Within our analyses, we thus had to account for the violation of the statistical assumption of uncorrelated error terms, due to the lack of independence of xenophobia ratings given by the same respondent. We thus estimated the effect of the variation of item dimensions (Level 1 variables) on xenophobia ratings within individual respondents, in calculating fixed effects (FE) models that control for between-respondent (Level 2) differences in the evaluation of these statements. Respondent characteristics (Level 2 variables; i.e., IM and EM) were considered by calculating two separate FE models including cross-level interactions, in order to examine whether IM and EM moderated the effect of the item dimensions on xenophobia ratings.

\section{Results}

\section{Impact of Item Dimensions on Xenophobia Ratings}

First, we ran an unconditional model with xenophobia ratings for the prejudice items as the dependent variable and no independent variables in the model. The intraclass correlation (ICC) coefficient indicated that a high proportion of $60.3 \%$ of the variance in xenophobia ratings could be attributed to the respondent level (Level 2). Thus, individuals tended to evaluate the four items that they received in a similar manner. Then, a FE model was calculated with xenophobia ratings as the dependent variable and the three item dimensions (topic, language, target group) as categorical independent variables (see Table A3 in the Supplementary Materials for descriptive statistics for the 24 prejudice items). ${ }^{9}$ The manipulation of the item dimensions accounted for approximately $13.4 \%$ of the within-variance, i.e., for the differences in xenophobia ratings within individual respondents. The model revealed significant main effects for all three manipulated

\footnotetext{
8) IM and EM showed a small positive association $(r=.11, p<.001)$. Factor analyses confirmed that IM and EM items loaded on two distinct factors.

9) Since for categorical predictor variables, as included in the models, standardized regression coefficients are less appropriate measures of effect size, simple regression coefficients $(b)$ are reported (see also Baguley, 2009).
} 
item dimensions on xenophobia ratings in relation to the respective levels set as reference categories (see Table 1). The topic to which a prejudicial statement referred significantly influenced its degree of subtlety. Prejudice items relating to the topic of economic utility were judged as most xenophobic, followed by items referring to danger/ inner security. Items pertaining to culture were judged as least xenophobic. Post-hoc pairwise comparisons (using Bonferroni corrections) confirmed that all three topics differed significantly $(p s<.001)$ from each other regarding their level of subtlety. Additionally, as expected, the language also significantly determined the subtlety of the prejudicial statements. Xenophobia ratings increased along the range of the linguistic phrasing: Weakly essentialist prejudicial statements were rated as least, and strongly essentialist items as most xenophobic. Pairwise comparisons with Bonferroni correction indicated that-except for the rather strongly and the strongly essentialist phrasing-all levels of the linguistic phrasing yielded significantly different xenophobia ratings $(p s<.001)$. Regarding the variation of the target group, analyses revealed, as hypothesized, that the same prejudicial statements were evaluated as more xenophobic when being directed at Turks than when being directed towards Muslims. ${ }^{10}$

Table 1

Model of Fixed Effects of Item Dimensions on Xenophobia Ratings

\begin{tabular}{|c|c|c|c|c|}
\hline \multirow[b]{2}{*}{ Predictors and parameters } & \multirow[b]{2}{*}{$b$} & \multirow[b]{2}{*}{$S E$} & \multicolumn{2}{|c|}{$95 \% \mathrm{CI}$} \\
\hline & & & $L L$ & $U L$ \\
\hline \multicolumn{5}{|l|}{ Item dimensions } \\
\hline \multicolumn{5}{|l|}{ Topic } \\
\hline \multicolumn{5}{|l|}{ Culture (ref.) } \\
\hline Economic utility & $0.431^{* * *}$ & 0.037 & 0.358 & 0.503 \\
\hline Danger & $0.247^{* * *}$ & 0.037 & 0.174 & 0.320 \\
\hline \multicolumn{5}{|l|}{ Language } \\
\hline \multicolumn{5}{|l|}{ Weakly essentialist (ref.) } \\
\hline Rather weakly essentialist & $0.334^{* * *}$ & 0.042 & 0.251 & 0.417 \\
\hline Rather strongly essentialist & $0.564^{* * *}$ & 0.042 & 0.482 & 0.647 \\
\hline Strongly essentialist & $0.618^{* * *}$ & 0.043 & 0.535 & 0.702 \\
\hline \multicolumn{5}{|l|}{ Target group } \\
\hline \multicolumn{5}{|l|}{ Muslims (ref.) } \\
\hline Turks & $0.071^{*}$ & 0.030 & 0.012 & 0.129 \\
\hline Intercept & $3.042^{* * *}$ & 0.039 & 2.966 & 3.118 \\
\hline$R_{\mathrm{within}}^{2}$ & .134 & & & \\
\hline$R_{\text {between }}^{2}$ & .014 & & & \\
\hline$R_{\text {overall }}^{2}$ & .054 & & & \\
\hline
\end{tabular}

\section{Impact of Motivations to Respond Without Prejudice}

In order to examine whether the impact of the item dimensions on xenophobia ratings depended on participants' motivations to respond without prejudice, the same FE models were calculated, now including cross-level interaction terms of the item dimensions and IM and EM, respectively. IM and EM were mean centered beforehand.

10) Before giving their xenophobia ratings, participants also indicated whether they (dis)agreed with the statements. Controlling for endorsement did not substantially change the main results; only the effect of the target group became insignificant. Interaction effects between item dimensions were also tested. Effects were uniform, except for significant interaction terms between linguistic phrasing and target group. Since interaction effects were not hypothesized a priori, they were not further discussed within this article. 


\section{Internal Motivation to Respond Without Prejudice}

Results (see Table 2) revealed significant interaction effects between all levels of the item dimension language and IM, indicating that IM moderated the effect of the linguistic phrasing on xenophobia ratings. With heightened levels of IM, individuals more strongly increased their xenophobia ratings in response to the shifts in the linguistic phrasing of the prejudicial statements from the weakly essentialist (reference category) to the rather weakly essentialist $(b=$ $0.168, p=.004)$, to the rather strongly essentialist $(b=0.125, p=.027)$, and to the strongly essentialist phrasing $(b=$ $0.179, p=.002)$. Similarly, the effect of the manipulation of the prejudicial statements' topic on xenophobia ratings was significantly moderated by IM. With higher IM, participants more strongly increased their xenophobia ratings in response to changes in the topic of the prejudicial statement from culture (reference category) to economic utility $(b=$ $0.143, p=.005)$, and to danger/ inner security $(b=0.120, p=.016)$. The interaction term between IM and the item dimension target group was not significant. Thus, largely in line with our hypothesis, the effect of the manipulation of the linguistic phrasing and topic on xenophobia ratings depended on respondents' IM.

Table 2

Model of Fixed Effects of Item Dimensions on Xenophobia Ratings With Cross-Level Interactions Between Item Dimensions and Respondents' Internal Motivation (IM) to Control Prejudice

\begin{tabular}{|c|c|c|c|c|}
\hline \multirow[b]{2}{*}{ Predictors and parameters } & \multirow[b]{2}{*}{$b$} & \multirow[b]{2}{*}{$S E$} & \multicolumn{2}{|c|}{$95 \% \mathrm{CI}$} \\
\hline & & & $L L$ & $U L$ \\
\hline \multicolumn{5}{|l|}{ Main effects: Item dimensions } \\
\hline \multicolumn{5}{|l|}{ Topic $^{\mathrm{a}}$} \\
\hline Economic utility & $0.428^{* * *}$ & 0.037 & 0.356 & 0.500 \\
\hline Danger & $0.246^{* * *}$ & 0.037 & 0.173 & 0.319 \\
\hline \multicolumn{5}{|l|}{ Language $^{b}$} \\
\hline Rather weakly essentialist & $0.336^{* * *}$ & 0.042 & 0.253 & 0.418 \\
\hline Rather strongly essentialist & $0.560^{* * *}$ & 0.042 & 0.478 & 0.642 \\
\hline Strongly essentialist & $0.617^{* * *}$ & 0.042 & 0.534 & 0.700 \\
\hline \multicolumn{5}{|l|}{ Target group ${ }^{c}$} \\
\hline Turks & $0.071^{*}$ & 0.030 & 0.013 & 0.129 \\
\hline \multicolumn{5}{|c|}{ Cross-level interactions: Item dimensions $x$ IM } \\
\hline \multicolumn{5}{|l|}{ Topic $^{\mathrm{a}} \mathrm{x}$ IM } \\
\hline Economic utility & $0.143^{* *}$ & 0.050 & 0.044 & 0.241 \\
\hline Danger & $0.120^{*}$ & 0.050 & 0.023 & 0.217 \\
\hline \multicolumn{5}{|l|}{ Language $^{b} \times$ IM } \\
\hline Rather weakly essentialist & $0.168^{* *}$ & 0.058 & 0.054 & 0.282 \\
\hline Rather strongly essentialist & $0.125^{*}$ & 0.056 & 0.014 & 0.236 \\
\hline Strongly essentialist & $0.179^{* *}$ & 0.058 & 0.066 & 0.292 \\
\hline \multicolumn{5}{|l|}{ Target group $^{c} \times$ IM } \\
\hline Turks & -0.009 & 0.040 & -0.087 & 0.070 \\
\hline Intercept & $3.044^{* * *}$ & 0.039 & 2.968 & 3.120 \\
\hline$R_{\text {within }}^{2}$ & .141 & & & \\
\hline$R_{\text {between }}^{2}$ & .128 & & & \\
\hline$R_{\text {overall }}^{2}$ & .122 & & & \\
\hline
\end{tabular}




\section{External Motivation to Respond Without Prejudice}

Results (see Table 3) further revealed significant interaction effects between all levels of the item dimension language and EM. With higher EM, individuals showed a weaker increase in their xenophobia ratings in response to the shifts in the linguistic phrasing of the prejudicial statements from the weakly essentialist (reference category) to the rather weakly essentialist $(b=-0.120, p<.001)$, to the rather strongly essentialist $(b=-0.070, p=.035)$, and to the strongly essentialist phrasing $(b=-0.153, p<.001)$. Additionally, with increasing EM, participants raised their xenophobia ratings less strongly to the shift from the culture topic (reference category) to the economic utility topic $(b=-0.121, p<.001)$. The interaction term between EM and the item dimension target group was not significant. Thus, mostly in line with our hypothesis, respondents' EM moderated the effects of the manipulation of the linguistic phrasing and specific levels of the topic dimension on xenophobia ratings.

\section{Table 3}

Model of Fixed Effects of Item Dimensions on Xenophobia Ratings With Cross-Level Interactions Between Item Dimensions and Respondents' External Motivation (EM) to Control Prejudice

\begin{tabular}{|c|c|c|c|c|}
\hline \multirow[b]{2}{*}{ Predictors and parameters } & \multirow[b]{2}{*}{$b$} & \multirow[b]{2}{*}{$S E$} & \multicolumn{2}{|c|}{$95 \% \mathrm{CI}$} \\
\hline & & & $L L$ & $U L$ \\
\hline \multicolumn{5}{|l|}{ Main effects: Item dimensions } \\
\hline \multicolumn{5}{|l|}{ Topic $^{\mathrm{a}}$} \\
\hline Economic utility & $0.432^{* * *}$ & 0.037 & 0.360 & 0.504 \\
\hline Danger & $0.244^{* * *}$ & 0.037 & 0.171 & 0.317 \\
\hline \multicolumn{5}{|l|}{ Language $^{b}$} \\
\hline Rather weakly essentialist & $0.329^{* * *}$ & 0.042 & 0.247 & 0.411 \\
\hline Rather strongly essentialist & $0.564^{* * *}$ & 0.042 & 0.482 & 0.646 \\
\hline Strongly essentialist & $0.622^{* * *}$ & 0.042 & 0.539 & 0.705 \\
\hline \multicolumn{5}{|l|}{ Target group $^{c}$} \\
\hline Turks & $0.069^{*}$ & 0.030 & 0.011 & 0.127 \\
\hline \multicolumn{5}{|c|}{ Cross-level interactions: Item dimensions x EM } \\
\hline \multicolumn{5}{|l|}{ Topic $^{\mathrm{a}} \mathrm{x}$ EM } \\
\hline Economic utility & $-0.121^{* * *}$ & 0.030 & -0.179 & -0.063 \\
\hline Danger & -0.052 & 0.030 & -0.110 & 0.006 \\
\hline \multicolumn{5}{|l|}{ Language $^{b} \times$ EM } \\
\hline Rather weakly essentialist & $-0.120^{* * *}$ & 0.034 & -0.186 & -0.053 \\
\hline Rather strongly essentialist & $-0.070^{*}$ & 0.033 & -0.135 & -0.005 \\
\hline Strongly essentialist & $-0.153^{* * *}$ & 0.035 & -0.220 & -0.085 \\
\hline \multicolumn{5}{|l|}{ Target group $^{c} \mathrm{x}$ EM } \\
\hline Turks & 0.027 & 0.024 & -0.020 & 0.073 \\
\hline Intercept & $3.046^{* * *}$ & 0.039 & 2.971 & 3.122 \\
\hline$R_{\text {within }}^{2}$ & .147 & & & \\
\hline$R_{\text {between }}^{2}$ & .023 & & & \\
\hline$R_{\text {overall }}^{2}$ & .064 & & & \\
\hline
\end{tabular}


We also ran an exploratory FE model with three-way cross-level interaction terms between item dimensions, IM and EM in predicting xenophobia ratings; none of them were significant. This indicates that the interaction effects of IM and EM with the item dimensions, respectively, work independently and in opposing directions, such that with higher IM and lower EM, respondents adjusted their xenophobia ratings more strongly to the item variations of the topic and linguistic phrasing.

\section{Discussion}

Current public debates, in which immigration has become one of the most controversial issues, are oftentimes characterized by ethnic prejudice. However, while some expressions of prejudice against ethnic groups seem to openly violate egalitarian norms, the xenophobic nature of other ethnically prejudicial comments seems to go rather unnoticed, apparently circumventing anti-prejudice norms. The current study sought to explore the nature of such subtle ways of ethnic prejudice expression and to examine which specific characteristics can disguise the prejudicial content of an utterance, making certain ethnically prejudicial statements subtler, i.e., less recognizable as xenophobic, than others. Adapting the logic of factorial survey experiments (e.g., Auspurg \& Hinz, 2015; Wallander, 2009), our results based on data from a German probability sample show that the subtlety of different ethnically prejudicial statements, i.e. their social perception as (not) xenophobic, systematically varies along three dimensions, i.e., topic, language and target group.

Regarding the impact of the topic on subtlety, results indicate that ethnically prejudicial statements implying alleged cultural incompatibilities (in this case regarding gender relations) between the respective target group and the majority in-group are especially subtle, being judged as least xenophobic, while those relating to danger/ inner security and economic utility were judged as more xenophobic. Interpreting these exploratory findings, we would argue that the comparable presence of these topics in the public discourse might not be indicative of how they are discussed. Particularly the issue of the 'cultural fit' of migrant groups into society-especially with regard to Turks and Muslims and concerning gender relations-might be discussed most controversially in Germany (but probably in other countries as well) and prejudicial comments referring to supposed differences in cultural values might also be harder to grasp and therefore harder to refute, possibly leading to a higher subtlety of such statements. Contextualizing our findings in terms of integrated threat theory (Stephan \& Stephan, 2000) one could-even though all utterances refer to supposed differences in core attributes (or values)-conceptualize the statements within the 'culture' topic as rather alluding to symbolic threats arising from immigration and multiculturalism, and those within the 'economic utility' and 'danger' topic as alluding to realistic threats, tentatively concluding that prejudicial statements relating to symbolic threats are especially subtle. Generally, our results suggest that certain topics indeed serve as subtler vehicles for communicating ethnic prejudice than others.

In accordance with our hypothesis, we also found that the specific language, i.e., the essentialist phrasing, employed within ethnically prejudicial statements influences their subtlety: Prejudicial statements that were phrased in a weakly essentialist manner, suggesting the potential alterability of the target group, provided the subtlest disguise, in being evaluated as least xenophobic, while those using a strongly essentialist language, implying an immutable inferiority of an ethnic group, were more strongly perceived as xenophobic. These findings complement previous social-psychological research on the role of the linguistic phrasing-specifically essentialist, abstract manners of describing group behaviors-for the perpetuation of (ethnic) prejudice (Assilaméhou et al., 2013; Beukeboom, 2014; Wigboldus et al., 2000). As also suggested by Douglas and Sutton $(2006,2010)$, our results indicate that people are sensitive to the derogatory implications of this linguistic feature, in perceiving ethnically prejudicial statements that are phrased highly essentialistically more strongly as xenophobic, while those statements that are phrased less essentialistically might, in not being readily identified as xenophobic, rather slip under the radar.

Furthermore, our results extend previous work on ethnic hierarchies (e.g., Hagendoorn, 1995), the general perceived acceptability of prejudice against different social groups (Crandall et al., 2002) as well as the impact of group labels (e.g., Kotzur et al., 2017) in revealing that the degree to which the xenophobic nature of single ethnically prejudicial statements is or is not recognized also depends on the group against which these are directed. In line with our hypothe- 
sis, prejudicial statements directed against Muslims were somewhat subtler than the same statements directed against Turks. This effect turned out to be small and it is likely, of course, that stronger differences would have been observed, if we had compared more dissimilar groups or employed obviously disparaging labels. However, it is noteworthy that the specific labels employed for the groups (rather than the fact they refer to completely distinct groups), without them being inherently derogatory, can indeed cause small differences in the subtlety of prejudicial statements. We would attribute this small target group difference to the fact that 'Muslims' represent the most controversially discussed group in the German migration discourse (e.g., Hierl, 2012) and are a broader ethno-religious group with blurrier boundaries, which might be harder to grasp, also as the target of racism. Thus, employing a broader, more negatively connoted minority group label seems to camouflage the xenophobic content of an ethnically prejudicial statement more strongly.

Moreover, largely corroborating our predictions, with increasing IM and decreasing EM, i.e., a stronger self-determined motivation to respond without prejudice (Butz \& Plant, 2009; Devine et al., 2002; see also Legault et al., 2007), individuals were more sensitive to features determining subtler or more blatant ways of ethnic prejudice expression. They more strongly adapted their evaluation of ethnically prejudicial statements as (not) xenophobic to the specific manner in which these prejudicial beliefs were expressed, in more strongly increasing their xenophobia ratings in response to those item variations along linguistic phrasing and topic that were found to be more blatant, identifying them more readily as prejudicial. Based on previous research indicating that individuals with higher IM and lower EM more strongly regulate prejudiced responses also within private assessments of explicit ethnic prejudice (e.g., Devine et al., 2002; Plant \& Devine, 1998), comparable to the current, anonymous survey setting, we interpret these individual differences in terms of the motivated efforts to devote-for one's self and in private-vigilance to the identification of prejudicial comments. We reason that these individuals, in being personally more committed to egalitarianism and rooting out (ethnic) prejudice, more strongly engaged in a conscientious processing of potentially prejudicial statements, increasing their responsiveness to the item variations. This interpretation might tentatively also be linked to theoretical models in the persuasion literature suggesting that motivations determine individuals' engagement in a deliberate, effortful processing of a message (e.g., Petty \& Cacioppo, 1986; for an overview see Bohner \& Dickel, 2011, pp. 403-405).

Taken together, the current findings add to research on the recognition of prejudice (e.g., Mae \& Carlston, 2005; Marti et al., 2000) in revealing that the subtlety of single ethnically prejudicial statements, as the degree to which these are (not) readily identified as xenophobic, can be systematically manipulated along specific dimensions and that individuals differ in their sensitivity to respond to such a manipulation of prejudicial statements. Building upon existing approaches on subtle, contemporary forms of explicit ethnic prejudice (e.g., Kinder \& Sears, 1981; McConahay, 1986; Pettigrew \& Meertens, 1995), the current study extends this line of research in taking an analytically new perspective: It shifted away from examining subtle prejudice as an individual-level attitude shaping intergroup relations (e.g., Rabinowitz et al., 2009) and laid the focus on the nature of the subtle ethnically prejudicial statements, i.e., consciously uttered beliefs that disfavor certain minority groups, themselves and how certain characteristics determine their social perception as (not) xenophobic.

When looking at our findings from a group norm perspective (Sherif \& Sherif, 1953; see also e.g., Crandall et al., 2002; Crandall et al., 2013), they show that expressions of ethnic prejudice are not uniformly perceived as xenophobic and hence a violation of dominant egalitarian norms. From this point of view, our results could be interpreted as a pattern of social acceptability (or a reflection of another social norm), mirroring which ethnically prejudicial beliefs are more or less strongly perceived as xenophobic, with this perception being crucially determined by characteristics of these statements, such as topic, target group and linguistic phrasing, that can contribute to a concealment of their prejudicial nature. Also, our findings indicate that especially individuals with higher self-determined motivations to avoid prejudice are more sensitive to these normative characteristics of subtler and blatant variations of ethnically prejudicial statements, identifying the latter more strongly as xenophobic. This social perception of ethnically prejudicial statements as (not) xenophobic should also be interpreted as a reflection of its political and social context, with the main study being conducted in Germany in the aftermath of the so-called refugee crisis, in which, after a period of welcoming, negative stereotypes of immigrants and refugees and controversies about immigration have been taking over again in news reporting (Hemmelmann \& Wegner, 2016), and the Alternative für Deutschland (AfD), a right-wing populist party, was shaping the public discourse, attracting continuously more voters with a strong anti-immigrant profile. Thus, the specific results on the subtlety of ethnically prejudicial statements, especially those relating to topics 
and target groups, should not to be regarded as fixed, but rather as subject to contextual factors, such as specific events and political agenda setting, with norms of social acceptability concerning (ethnic) prejudice (e.g., Crandall et al., 2013) and the borders of 'what is sayable' and what is regarded as (not) xenophobic being continuously negotiated. Against the backdrop of the increasing global success of right-wing populist and extremist forces and their anti-immigrant rhetoric, one might also discuss whether social norms have been beginning to become more lenient again concerning which forms of prejudicial statements are regarded as 'not xenophobic'. Longitudinal research would be necessary to monitor such trends in social norms regarding the perception of ethnically prejudicial statements. Nevertheless, despite such a potential temporal and contextual volatility, the general mechanism behind the subtlety of explicit ethnic prejudice illuminated in this study, in being determined by features such as topic, target group and linguistic phrasing, should be less fluctuating and applicable to other contexts as well.

Also, the current findings provide valuable insights into the psychological underpinnings of the dynamics within the current public and political migration discourse. Certain variations of ethnically prejudicial beliefs are subtler, in being less readily perceived as xenophobic and hence in conflict with egalitarian norms. Thus, on the one hand, individuals might endorse and express such beliefs, without recognizing their prejudicial nature and hence without perceiving them to compromise anti-prejudice standards or an egalitarian self-image. On the other hand, recipients of such expressions of ethnic prejudice might, in not recognizing their xenophobic content, potentially be less inclined to oppose their proponents. Also, for (professional) communicators, the subtlety of certain ways of verbalizing ethnic prejudice might even have a 'functional value' and could be deliberately exploited to express ethnically prejudicial arguments without openly violating anti-prejudice norms. Such rhetorical strategies might be especially 'effective' in passing over prejudicial statements to or without repelling those people who have strongly self-determined motivations to avoid prejudice, as they were most sensitive to the features determining subtler and more blatant ways of expressing ethnic prejudice, reacting more strongly to those variations of the prejudicial statements that were found to be more blatant, in evaluating them more readily as xenophobic. In that way, subtler expressions of ethnic prejudice might surreptitiously contribute to a perpetuation of negative beliefs concerning ethnic minorities group in current migration discourses, thereby potentially reinforcing ethnic inequalities.

The current findings also have practical implications for interventions aimed at creating awareness for subtle forms of ethnic prejudice in the public discourse, in pointing out the need to identify those aspects of prejudicial statements that are especially effective in concealing their xenophobic nature.

From a methodological perspective, our results demonstrate the fruitfulness of adapting the rationale of factorial survey experiments to social-psychological prejudice research. Also, the fact that the manipulation of certain characteristics can affect the degree to which statements are perceived as (not) xenophobic emphasizes the need to consider even small changes when developing items aimed at tapping subtler forms of ethnic prejudice.

\section{Limitations and Future Directions}

Our study also carries some limitations and leaves open questions for future research.

First, our results based on a German probability sample may not be readily generalizable to other contexts, as national particularities might-as mentioned before-influence which features are especially important in shaping the subtlety of ethnically prejudicial statements, e.g., depending on the presence of different minority groups or the dominance of certain topics in migration debates. Nevertheless, we assume that the general mechanism of topic, linguistic phrasing, and target group determining the subtlety of prejudicial statements would also be applicable to other contexts.

Relating to this aspect, we do not regard the dimensions and respective levels manipulated here as exhaustive, but it was rather our aim to introduce a new analytical perspective and to provide a first investigation of characteristics contributing to the concealment of a statement's prejudicial nature. Further research is warranted to investigate other variations, such as the impact of different target group labels, e.g., similar and more distinct ones, or other dimensions, e.g., the source (and its credibility), of a prejudicial statement. Also, one could revise the essentialist linguistic phrasing employed here. The data from our additional survey ${ }^{11}$ suggest that the perceived unchangeability of the target group's

11) See Footnote 7. 
attribute particularly varied between the first and the three stronger levels of the language dimension, whereby the locus of that varying controllability was rather perceived to lie within others than the target group itself. This should be borne in mind when interpreting the results. Further research might more closely investigate variations of prejudicial statements that imply different loci of controllability of a group's negative attribute or behavior.

Moreover, although also other previous studies on prejudice employed interviewer-administered survey methods (e.g., Zick, Wolf, et al., 2008) and our analysis strategy (i.e., FE models) cancelled out individual differences in social desirability, we cannot completely rule out a socially desirable over-statement of xenophobia ratings within the sample as a whole (see e.g., Kreuter, Presser, \& Tourangeau, 2008). However, this would have rather led to an underestimation of the experimental effects. Additionally, the response behavior of high-EM individuals suggests that the interview context was perceived as a rather anonymous setting. Nevertheless, future research might explore different survey modes when assessing the subtlety of prejudicial statements.

Also, due to the constraints within telephone interviews, we could only include a limited number of IM and EM items and the reliability of the shortened EM scale was not fully satisfactory. Results concerning EM should thus be interpreted with some caution, presumably reflecting a rather conservative, attenuated estimation of the moderating effect of EM (e.g., Henson, 2001). Yet, we think that the possibility of drawing a probability sample in a telephone survey strongly enhances the generalizability of the results compared to studies with convenience samples. Nevertheless, further studies employing the full IM and EM scales are needed to investigate whether these yield similar or larger effect sizes.

Furthermore, individual differences in the responsiveness to a systematic manipulation of prejudice items have to our knowledge not been investigated before. Hence, additional studies are needed to corroborate our theoretical conclusions regarding the impact of IM and EM on the scrutiny with which prejudicial statements are processed. Also, as discussed before, it is important to emphasize that the current results pertain to a private survey setting. It would be worthwhile to particularly investigate the moderating role of EM in public contexts, where answers are observable, in which one might EM even expect to work in the opposite direction. Moreover, rather than providing an extensive investigation of a variety of moderators, we primarily aimed to substantiate the theoretical value of our systematic manipulation of prejudicial statements and considered IM and EM as motivational constructs most plausibly affecting individuals' sensitivity to features determining subtler or more blatant ways of expressing ethnic prejudice. We post-hoc conducted exploratory analyses on the moderating role of other individual difference variables included in the larger telephone survey (see Tables A4-A8 in the Supplementary Materials), whereby the direction of the interaction effects of the item dimensions with social dominance orientation and egalitarian self-concept-although mostly not statistically significant-at least tentatively matches our theoretical considerations regarding individuals' responsiveness to the item variations. Further studies could examine other potential moderators, e.g., individuals' general bias awareness (Perry, Murphy, \& Dovidio, 2015).

\section{Conclusion}

Notwithstanding these caveats, we believe that the current findings, based on a comparably large random population sample, contribute to research on subtle forms of explicit ethnic prejudice, by showing how even small changes in single ethnically prejudicial statements along their topic, language (i.e., essentialist phrasing), and target group can influence the degree to which these utterances are perceived as (not) xenophobic. The idea that the subtlety of prejudicial statements is systematically manipulable could also be extended to research on other social prejudices, such as sexism and homophobia. In the context of current anti-immigrant discourses, our results clearly demonstrate that attention should be devoted to the specific manner in which ethnic prejudice is communicated: In disguising their xenophobic nature and being less readily recognized as prejudicial, such subtle expressions of ethnic prejudice might act especially surreptitiously in perpetuating negative beliefs about ethnic minority groups and potentially reinforcing ethnic inequalities, while avoiding an open violation of egalitarian, anti-prejudice norms. 
Funding: This work was supported in part by a grant from Germany's Federal Government Commissioner for Migration, Refugees and Integration, and in part by a grant from the Hertie Foundation under grant number [P1140035].

Acknowledgments: The authors wish to thank Steffen Beigang, Tim Müller, and colleagues from the Language and Migration Group for their valuable comments on this manuscript, as well as Markus Schopp for his assistance during data collection.

Competing Interests: The authors have declared that no competing interests exist.

\section{Supplementary Materials}

The Supplementary Materials contain an overview of all constructs included in the larger telephone survey, an English translation of the experimental materials used in the study, descriptive statistics, results from further exploratory analyses as well results from an additional online survey (for unrestricted access see Index of Supplementary Materials below).

\section{Index of Supplementary Materials}

Fetz, K., \& Kroh, M. (2021). Supplementary materials to "Prejudice in disguise: Which features determine the subtlety of ethnically prejudicial statements?" [Additional information and analyses]. PsychOpen GOLD. https://doi.org/10.23668/psycharchives.4781

\section{References}

Abrams, D., Houston, D. M., van de Vyver, J., \& Vasiljevic, M. (2015). Equality hypocrisy, inconsistency, and prejudice: The unequal application of the universal human right to equality. Peace and Conflict, 21, 28-46. https://doi.org/10.1037/pac0000084

Asbrock, F. (2010). Stereotypes of social groups in Germany in terms of warmth and competence. Social Psychology, 41, 76-81. https://doi.org/10.1027/1864-9335/a000011

Assilaméhou, Y., Lepastourel, N., \& Testé, B. (2013). How the linguistic intergroup bias affects group perception: Effects of language abstraction on generalization to the group. The fournal of Social Psychology, 153, 98-108. https://doi.org/10.1080/00224545.2012.711380

Augoustinos, M., \& Every, D. (2007a). Contemporary racist discourse: Taboos against racism and racist accusations. In A. Weatherell, B. Watson, \& C. Gallois (Eds.), Language, discourse and social psychology (pp. 233-254). London, United Kingdom: Palgrave Macmillan.

Augoustinos, M., \& Every, D. (2007b). The language of "race" and prejudice: A discourse of denial, reason, and liberal-practical politics. Journal of Language and Social Psychology, 26, 123-141. https://doi.org/10.1177/0261927X07300075

Auspurg, K., \& Hinz, T. (2015). Factorial survey experiments. Thousand Oaks, CA, USA: SAGE.

Baguley, T. (2009). Standardized or simple effect size: What should be reported? British fournal of Psychology, 100, 603-617. https://doi.org/10.1348/000712608X377117

Baron, R. S., Burgess, M. L., \& Kao, C. F. (1991). Detecting and labeling prejudice: Do female perpetrators go undetected? Personality and Social Psychology Bulletin, 17, 115-123. https://doi.org/10.1177/014616729101700201

Bauder, H. (2008). Media discourse and the new German immigration law. fournal of Ethnic and Migration Studies, 34, 95-112. https://doi.org/10.1080/13691830701708783

Berry, M., Garcia-Blanco, I., \& Moore, K. (2015). Press coverage of the refugee and migrant crisis in the EU: A content analysis of five European countries. Geneva, Switzerland: UNHCR.

Beukeboom, C. J. (2014). Mechanisms of linguistic bias: How words reflect and maintain stereotypic expectancies. In J. P. Forgas, O. Vincze, \& J. László (Eds.), Social cognition and communication (pp. 313-330). New York, NY, USA: Psychology Press.

Billig, M. (1988). The notion of 'prejudice': Some rhetorical and ideological aspects. Text, 8, 91-110.

https://doi.org/10.1515/text.1.1988.8.1-2.91 
Bohner, G., \& Dickel, N. (2011). Attitudes and attitude change. Annual Review of Psychology, 62, 391-417. https://doi.org/10.1146/annurev.psych.121208.131609

Bonilla-Silva, E. (2002). The linguistics of color blind racism: How to talk nasty about Blacks without sounding "racist". Critical Sociology, 28, 41-64. https://doi.org/10.1177/08969205020280010501

Butz, D. A., \& Plant, E. A. (2009). Prejudice control and interracial relations: The role of motivation to respond without prejudice. fournal of Personality, 77, 1311-1341. https://doi.org/10.1111/j.1467-6494.2009.00583.x

Carnaghi, A., \& Maass, A. (2007). In-group and out-group perspectives in the use of derogatory group labels: Gay versus Fag. Fournal of Language and Social Psychology, 26, 142-156. https://doi.org/10.1177/0261927X07300077

Caviedes, A. (2015). An emerging 'European' news portrayal of immigration? Journal of Ethnic and Migration Studies, $41,897-917$. https://doi.org/10.1080/1369183X.2014.1002199

Condor, S., Figgou, L., Abell, J., Gibson, S., \& Stevenson, C. (2006). ‘They're not racist ...’: Prejudice denial, mitigation and suppression in dialogue. British fournal of Social Psychology, 45, 441-462. https://doi.org/10.1348/014466605X66817

Crandall, C. S., Eshleman, A., \& O’Brien, L. (2002). Social norms and the expression and suppression of prejudice: The struggle for internalization. Journal of Personality and Social Psychology, 82, 359-378. https://doi.org/10.1037/0022-3514.82.3.359

Crandall, C. S., Ferguson, M. A., \& Bahns, A. J. (2013). When we see prejudice: The normative window and social change. In C. Stangor \& C. S. Crandall (Eds.), Stereotyping and prejudice: Frontiers of social psychology (pp. 53-69). New York, NY, USA: Psychology Press.

Deci, E. L., \& Ryan, R. M. (2000). The "what" and "why” of goal pursuits: Human needs and the self-determination of behavior. Psychological Inquiry, 11, 227-268. https://doi.org/10.1207/S15327965PLI1104_01

Devine, P. G., Plant, E. A., Amodio, D. M., Harmon-Jones, E., \& Vance, S. L. (2002). The regulation of explicit and implicit race bias: The role of motivations to respond without prejudice. Fournal of Personality and Social Psychology, 82, 835-848. https://doi.org/10.1037/0022-3514.82.5.835

Dickson, K. R. (2012). All prejudices are not created equal: Different responses to subtle versus blatant expressions of prejudice (Doctoral thesis, University of Western Ontario, London, ON, Canada). Retrieved from https://ir.lib.uwo.ca/etd/704

Douglas, K. M., \& Sutton, R. M. (2006). When what you say about others says something about you: Language abstraction and inferences about describers' attitudes and goals. Journal of Experimental Social Psychology, 42, 500-508. https://doi.org/10.1016/j.jesp.2005.06.001

Douglas, K. M., \& Sutton, R. M. (2010). By their words ye shall know them: Language abstraction and the likeability of describers. European fournal of Social Psychology, 40, 366-374. https://doi.org/10.1002/ejsp.634

Dovidio, J. F. (2001). On the nature of contemporary prejudice: The third wave. fournal of Social Issues, 57, 829-849. https://doi.org/10.1111/0022-4537.00244

Dovidio, J. F., \& Gaertner, S. L. (1986). Prejudice, discrimination, and racism: Historical trends and contemporary approaches. In J. F. Dovidio \& S. L. Gaertner (Eds.), Prejudice, discrimination and racism (pp. 1-34). Orlando, FL, USA: Academic Press.

Eberl, J.-M., Meltzer, C. E., Heidenreich, T., Herrero, B., Theorin, N., Lind, F., . . Strömbäck, J. (2018). The European media discourse on immigration and its effects: A literature review. Annals of the International Communication Association, 42, $207-223$. https://doi.org/10.1080/23808985.2018.1497452

Fasoli, F., Paladino, M. P., Carnaghi, A., Jetten, J., Bastian, B., \& Bain, P. G. (2016). Not “just words": Exposure to homophobic epithets leads to dehumanizing and physical distancing from gay men. European fournal of Social Psychology, 46, 237-248. https://doi.org/10.1002/ejsp.2148

Fehr, J., \& Sassenberg, K. (2010). Willing and able: How internal motivation and failure help to overcome prejudice. Group Processes \& Intergroup Relations, 13, 167-181. https://doi.org/10.1177/1368430209343116

Gaertner, S. L., \& Dovidio, J. F. (1986). The aversive form of racism. In J. F. Dovidio \& S. L. Gaertner (Eds.), Prejudice, discrimination, and racism (pp. 61-89). Orlando, FL, USA: Academic Press.

Gelman, S. A., Ware, E. A., \& Kleinberg, F. (2010). Effects of generic language on category content and structure. Cognitive Psychology, 61, 273-301. https://doi.org/10.1016/j.cogpsych.2010.06.001

Geschke, D., Sassenberg, K., Ruhrmann, G., \& Sommer, D. (2010). Effects of linguistic abstractness in the mass media: How newspaper articles shape readers' attitudes toward migrants. fournal of Media Psychology, 22, 99-104.

https://doi.org/10.1027/1864-1105/a000014 
Häder, S., \& Gabler, S. (1998). Ein neues Stichprobendesign für telefonische Umfragen in Deutschland [A new sampling design for telephone surveys in Germany]. In S. Gabler, S. Häder, \& J. H. P. Hoffmeyer-Zlotnik (Eds.), Telefonstichproben in Deutschland (pp. 69-88). Opladen/Wiesbaden, Germany: Westdeutscher Verlag.

Hagendoorn, L. (1995). Intergroup biases in multiple group systems: The perception of ethnic hierarchies. European Review of Social Psychology, 6, 199-228. https://doi.org/10.1080/14792779443000058

Hall, E. V., Phillips, K. W., \& Townsend, S. S. M. (2015). A rose by any other name? The consequences of subtyping "AfricanAmericans" from "Blacks”. Journal of Experimental Social Psychology, 56, 183-190. https://doi.org/10.1016/j.jesp.2014.10.004

Haslam, N., Rothschild, L., \& Ernst, D. (2000). Essentialist beliefs about social categories. British fournal of Social Psychology, 39, 113-127. https://doi.org/10.1348/014466600164363

Hemmelmann, P., \& Wegner, S. (2016). Flüchtlingsdebatte im Spiegel von Medien und Parteien: Ein Überblick [The refugee debate in the mirror of media and parties: An overview]. Communicatio Socialis, 49, 21-38. https://doi.org/10.5771/0010-3497-2016-1-21

Henry, P. J., \& Sears, D. O. (2002). The symbolic racism 2000 scale. Political Psychology, 23, 253-283. https://doi.org/10.1111/0162-895X.00281

Henson, R. K. (2001). Understanding internal consistency reliability estimates: A conceptual primer on coefficient alpha. Measurement \& Evaluation in Counseling \& Development, 34, 177-189. https://doi.org/10.1080/07481756.2002.12069034

Hierl, K. (2012). Die Islamisierung der deutschen Integrationsdebatte: Zur Konstruktion kultureller Identitäten, Differenzen und Grenzziehungen im postkolonialen Diskurs [The Islamization of the German debate on integration: On the construction of cultural identities, differences and demarcations in the post-colonial discourse]. Berlin, Germany: LIT.

Holzberg, B., Kolbe, K., \& Zaborowski, R. (2018). Figures of crisis: The delineation of (un)deserving refugees in the German media. Sociology, 52, 534-550. https://doi.org/10.1177/0038038518759460

Inman, M. L., \& Baron, R. S. (1996). Influence of prototypes on perceptions of prejudice. fournal of Personality and Social Psychology, 70, 727-739. https://doi.org/10.1037/0022-3514.70.4.727

Kinder, D. R., \& Sears, D. O. (1981). Prejudice and politics: Symbolic racism versus racial threats to the good life. fournal of Personality and Social Psychology, 40, 414-431. https://doi.org/10.1037/0022-3514.40.3.414

Kotzur, P. F., Forsbach, N., \& Wagner, U. (2017). Choose your words wisely: Stereotypes, emotions, and action tendencies toward fled people as a function of the group label. Social Psychology, 48, 226-241. https://doi.org/10.1027/1864-9335/a000312

Kreuter, F., Presser, S., \& Tourangeau, R. (2008). Social desirability bias in CATI, IVR, and web surveys: The effects of mode and question sensitivity. Public Opinion Quarterly, 72, 847-865. https://doi.org/10.1093/poq/nfn063

Legault, L., Green-Demers, I., Grant, P., \& Chung, J. (2007). On the self-regulation of implicit and explicit prejudice: A selfdetermination theory perspective. Personality and Social Psychology Bulletin, 33, 732-749. https://doi.org/10.1177/0146167206298564

Maass, A., Salvi, D., Arcuri, L., \& Semin, G. R. (1989). Language use in intergroup contexts: The linguistic intergroup bias. Journal of Personality and Social Psychology, 57, 981-993. https://doi.org/10.1037/0022-3514.57.6.981

Mae, L., \& Carlston, D. E. (2005). Hoist on your own petard: When prejudiced remarks are recognized and backfire on speakers. Journal of Experimental Social Psychology, 41, 240-255. https://doi.org/10.1016/j.jesp.2004.06.011

Manganelli Rattazzi, A. M., \& Volpato, C. (2003). Social desirability of subtle and blatant prejudice scales. Psychological Reports, 92, 241-250. https://doi.org/10.2466/pr0.2003.92.1.241

Marti, M. W., Bobier, D. M., \& Baron, R. S. (2000). Right before our eyes: The failure to recognize non-prototypical forms of prejudice. Group Processes \& Intergroup Relations, 3, 403-418. https://doi.org/10.1177/1368430200003004005

McAuliffe, M., \& Ruhs, M. (Eds.). (2017). World Migration Report 2018. Geneva, Switzerland: International Organization for Migration. McConahay, J. B. (1986). Modern racism, ambivalence, and the modern racism scale. In J. F. Dovidio \& S. L. Gaertner (Eds.), Prejudice, discrimination and racism (pp. 91-126). San Diego, CA, USA: Academic Press.

McConahay, J. B., Hardee, B. B., \& Batts, V. (1981). Has racism declined in America? It depends on who is asking and what is asked. Journal of Conflict Resolution, 25, 563-579. https://doi.org/10.1177/002200278102500401

Monteith, M. J., Lybarger, J. E., \& Woodcock, A. (2009). Schooling the cognitive monster: The role of motivation in the regulation and control of prejudice. Social and Personality Psychology Compass, 3, 211-226. https://doi.org/10.1111/j.1751-9004.2009.00177.x

Pearson, A. R., Dovidio, J. F., \& Gaertner, S. L. (2009). The nature of contemporary prejudice: Insights from aversive racism. Social and Personality Psychology Compass, 3, 314-338. https://doi.org/10.1111/j.1751-9004.2009.00183.x 
Perry, S. P., Murphy, M. C., \& Dovidio, J. F. (2015). Modern prejudice: Subtle, but unconscious? The role of bias awareness in Whites' perceptions of personal and others' biases. Fournal of Experimental Social Psychology, 61, 64-78.

https://doi.org/10.1016/j.jesp.2015.06.007

Pettigrew, T. F., \& Meertens, R. W. (1995). Subtle and blatant prejudice in western Europe. European fournal of Social Psychology, 25, 57-75. https://doi.org/10.1002/ejsp.2420250106

Pettigrew, T. F., \& Meertens, R. W. (1996). The verzuiling puzzle: Understanding Dutch intergroup relations. Current Psychology, 15, 3-13. https://doi.org/10.1007/BF02686929

Petty, R. E., \& Cacioppo, J. T. (1986). The elaboration likelihood model of persuasion. In L. Berkowitz (Ed.), Advances in experimental social psychology (pp. 123-205). New York, NY, USA: Academic Press.

Plant, E. A., \& Devine, P. G. (1998). Internal and external motivation to respond without prejudice. fournal of Personality and Social Psychology, 75, 811-832. https://doi.org/10.1037/0022-3514.75.3.811

Prentice, D. A., \& Miller, D. T. (2007). Psychological essentialism of human categories. Current Directions in Psychological Science, 16, 202-206. https://doi.org/10.1111/j.1467-8721.2007.00504.x

Quinsaat, S. (2014). Competing news frames and hegemonic discourses in the construction of contemporary immigration and immigrants in the United States. Mass Communication \& Society, 17, 573-596. https://doi.org/10.1080/15205436.2013.816742

Rabinowitz, J. L., Sears, D. O., Sidanius, J., \& Krosnick, J. A. (2009). Why do White Americans oppose race-targeted policies? Clarifying the impact of symbolic racism. Political Psychology, 30, 805-828. https://doi.org/10.1111/j.1467-9221.2009.00726.x

Rhodes, M., Leslie, S.-J., \& Tworek, C. M. (2012). Cultural transmission of social essentialism. Proceedings of the National Academy of Sciences of the United States of America, 109, 13526-13531. https://doi.org/10.1073/pnas.1208951109

Rios, K. (2013). Right-wing authoritarianism predicts prejudice against "homosexuals" but not "gay men and lesbians". Journal of Experimental Social Psychology, 49, 1177-1183. https://doi.org/10.1016/j.jesp.2013.05.013

Rios, K., \& Ingraffia, Z. A. (2016). Judging the actions of “whistle-blowers" versus "leakers": Labels influence perceptions of dissenters who expose group misconduct. Group Processes \& Intergroup Relations, 19, 553-569. https://doi.org/10.1177/1368430216638537

Schwarz, N., Strack, F., Hippler, H.-J., \& Bishop, G. (1991). The impact of administration mode on response effects in survey measurement. Applied Cognitive Psychology, 5, 193-212. https://doi.org/10.1002/acp.2350050304

Semin, G. R., \& Fiedler, K. (1988). The cognitive functions of linguistic categories in describing persons: Social cognition and language. Journal of Personality and Social Psychology, 54, 558-568. https://doi.org/10.1037/0022-3514.54.4.558

Sherif, M., \& Sherif, C. W. (1953). Groups in harmony and tension. New York, NY, USA: Harper and Brothers.

Snellman, A., \& Ekehammar, B. (2005). Ethnic hierarchies, ethnic prejudice, and social dominance orientation. fournal of Community \& Applied Social Psychology, 15, 83-94. https://doi.org/10.1002/casp.812

Spielhaus, R. (2013). Vom Migranten zum Muslim und wieder zurück: Die Vermengung von Integrations- und Islamthemen in Medien, Politik und Forschung [From migrant to Muslim and back again: The blending of integration- and Islam-related topics in media, politics and research]. In D. Halm \& H. Meyer (Eds.), Islam und die deutsche Gesellschaft (pp. 169-194). Wiesbaden, Germany: Springer VS.

Statistisches Bundesamt. (2020). Bevölkerung und Erwerbstätigkeit: Ausländische Bevölkerung. Ergebnisse des Ausländerzentralregisters [Population and employment: Foreign population: Results from the central register of foreign nationals] (Fachserie 1 Reihe 2). Wiesbaden, Germany: Statistisches Bundesamt.

Stephan, W. G., \& Stephan, C. W. (2000). An integrated threat theory of prejudice. In S. Oskamp (Ed.), Reducing prejudice and discrimination (pp. 23-45). Mahwah, NJ, USA: Erlbaum.

Sue, D. W., Capodilupo, C. M., Torino, G. C., Bucceri, J. M., Holder, A. M. B., Nadal, K. L., \& Esquilin, M. (2007). Racial microaggressions in everyday life: Implications for clinical practice. The American Psychologist, 62, 271-286. https://doi.org/10.1037/0003-066X.62.4.271

Swim, J. K., Scott, E. D., Sechrist, G. B., Campbell, B., \& Stangor, C. (2003). The role of intent and harm in judgments of prejudice and discrimination. Journal of Personality and Social Psychology, 84, 944-959. https://doi.org/10.1037/0022-3514.84.5.944

van der Linden, M., \& Jacobs, L. (2017). The impact of cultural, economic, and safety issues in Flemish television news coverage (2003-13) of North African immigrants on perceptions of intergroup threat. Ethnic and Racial Studies, 40, $2823-2841$. https://doi.org/10.1080/01419870.2016.1229492

van Dijk, T. A. (1992). Discourse and the denial of racism. Discourse \& Society, 3, 87-118. https://doi.org/10.1177/0957926592003001005 
van Dijk, T. A. (2002). Discourse and racism. In D. T. Goldberg \& J. Solomos (Eds.), A companion to racial and ethnic studies (pp. 145159). Malden, MA, USA: Blackwell.

Wallander, L. (2009). 25 years of factorial surveys in sociology: A review. Social Science Research, 38, 505-520. https://doi.org/10.1016/j.ssresearch.2009.03.004

West, K., \& Hewstone, M. (2012). Relatively socially acceptable prejudice within and between societies. Fournal of Community \& Applied Social Psychology, 22, 269-282. https://doi.org/10.1002/casp.1112

Wigboldus, D. H. J., Semin, G. R., \& Spears, R. (2000). How do we communicate stereotypes? Linguistic bases and inferential consequences. Journal of Personality and Social Psychology, 78, 5-18. https://doi.org/10.1037/0022-3514.78.1.5

Zick, A., Pettigrew, T. F., \& Wagner, U. (2008). Ethnic prejudice and discrimination in Europe. fournal of Social Issues, 64, $233-251$. https://doi.org/10.1111/j.1540-4560.2008.00559.x

Zick, A., Wolf, C., Küpper, B., Davidov, E., Schmidt, P., \& Heitmeyer, W. (2008). The syndrome of group-focused enmity: The interrelation of prejudices tested with multiple cross-sectional and panel data. Journal of Social Issues, 64, 363-383.

https://doi.org/10.1111/j.1540-4560.2008.00566.x 